\title{
Determination and validation of off-target activities of anti-CD44 variant 6 antibodies using protein biochips and tissue microarrays
}

\author{
Angelika Lueking1', Jens Beator, Elisabeth Patz², Stefan Müllner, \\ Gabor Mehes ${ }^{3}$, and Peter Amersdorfer ${ }^{2}$ \\ 1 Protagen AG, Dortmund, Germany, ${ }^{2}$ Oridis-Biomed GmbH, Graz, Austria, and \\ 3 University of Debrecen, Debrecen, Hungary
}

BioTechniques 45:Pi-Pv (October 2008)

doi $10.2144 / 000112898$

We describe a novel procedure for determination and validation of off-target activities of anti-cluster designation antigen identity 44 (CD44) variant 6 recombinant antibodies by combining two complementary technology platforms; namely UNIchip AV-400, containing a printed serial dilution of CD44 variant 6 and approximately 400 different human proteins, and TISSOMICS, enabling human tissue microarray analysis in high-throughput mode. We have analyzed the performance of two human monoclonal recombinant antibodies directed against CD44 variant 6 protein, BMS 116 and BMS 125, in a blinded study. The antibodies exhibit a clear differentiation with regard to their binding profiles in the two systems. BMS 116 shows a low degree of specificity in the normal human Food and Drug Administration (FDA) tissue panel, which was confirmed by binding to more than 206 proteins on the protein biochip. In contrast, BMS 125 gives a highly selective membranous staining on selected human epithelial tissue components with no off-target activities observed on the protein biochip. Additionally, antibody BMS 125 shows a higher sensitivity to its antigen CD44 variant 6 than antibody BMS 116 as determined by the protein biochip.

\section{INTRODUCTION}

Therapeutic antibodies represent one of the fastest growing areas of the pharmaceutical industry. There are currently 20 monoclonal antibodies in the market that have been approved by the Food and Drug Administration (FDA) and over 300 in various stages of clinical development. In addition, there has been tremendous progress in designing innovative and complex methods for faster antibody development-in vitro evolution platforms such as phage display (1) or yeast display (2), transgenic mouse systems producing fully human antibodies such as XenoMouse technology (3), or UltiMab technology (4). While these processes have increased the availability of monoclonal antibodies for development as therapeutic or diagnostic products, it has become a challenging task to validate, prioritize, and select the best antibody from a vast pool of potential candidates. Protein microarrays and tissue microarrays (TMAs) have gained increasing importance in biomedical research programs and have the potential to aid in selection of the most specific antibody candidates (5-7). Here we apply a new combination of TMAs and protein biochips to characterize and validate the binding specificity of anti-cluster designation antigen identity 44 (CD44) variant 6 antibodies, BMS 116 and 125. CD44 is a membrane glycoprotein that functions as lymph node homing receptor in lymphocyte activation and is involved in homo- and heterotypic cell adhesion $(8,9)$. In several tumor cell lines the expression of splice variants (CD44v6 and CD44v7) are correlated with the metastatic potential and confer an advantage in the early steps of the metastatic cascade (10). Thus, expression of CD44 has been proposed to be associated with malignant behavior of tumors like invasive growth and formation of metastasis. We have chosen the CD44 variant 6 antigen model from the point of medical relevance and availability of recombinant antibodies for this study.

\section{MATERIALS AND METHODS}

\section{Human TMA (FDA Panel)}

In total, 27 types of formaldehydefixed and paraffin-embedded (FFPE) normal human tissues were collected and processed to obtain a TMA containing triplicate tissue cores of $0.6 \mathrm{~mm}$ in diameter. All specimens were fixed in buffered $5 \%$ formaldehyde solution and embedded in paraffin according to standard operating procedures. Four-micrometer-thick sections were routinely stained with hematoxylin and eosin; following the guidelines of the FDA commission (11), 27 of 32 tissue
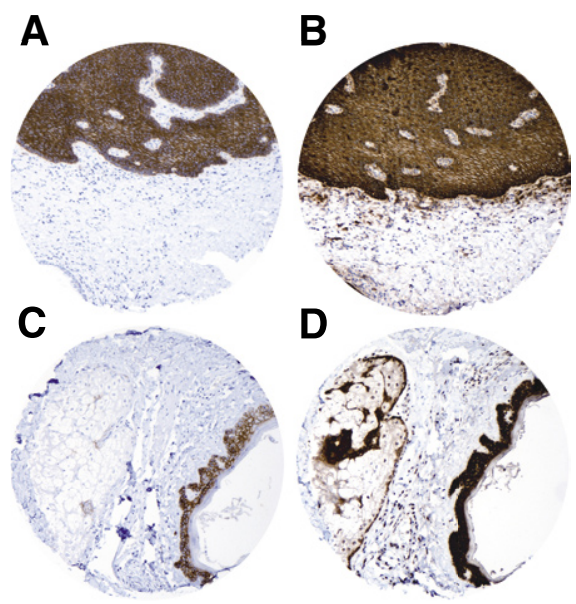

D

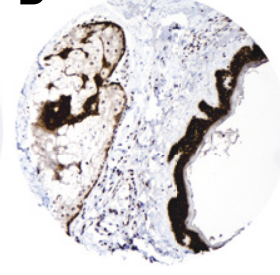

Figure 1. Immunohistochemistry (IHC) staining. Staining of identical cores from the normal esophagus mucosa (A, B), and normal skin (C, D). Squamous cell epithelium (upper half of both images) strongly express cluster designation antigen identity 44 (CD44) variant 6 leading to an intense IHC reaction for both antibody BMS 125 (A) and BMS 116 (B). The submucosal connective tissue containing leukocytes, fibrocytes, and capillary endothelial cells also shows positivity for BMS 116 (B) but not for BMS 125 (A). IHC staining of identical cores from the normal skin. Squamous cell epithelium (right side in both images) stained strongly positive for both BMS 125 (C) and BMS 116 (D), although the highly selective membrane staining is mixed with a cytoplasmic reaction of intermediate intensity. A sebaceous gland presents with a focal reaction (most probably myoepithelial cells) with BMS 125 (C) and with a strong membrane and nuclear staining when BMS 116 (D) was applied.

types of well-preserved and high-quality normal tissues are represented (three different samples per tissue type, three representative cores per sample): suprarenal cortex, uterus, breast, cerebellum, cerebral cortex, kidney cortex, liver, lung, colon mesothelium, ovary, skin, spleen, stomach, striated muscle, colon, tonsil, esophagus, myocardium, duodenum, pancreas, peripheral nerve, pituitary, prostate, salivary grand, testis, thyroid gland, and bone marrow. Some of the tissues/cell types required by the FDA have also been included, but not as isolated samples (e.g., endothelium, mesothelium, smooth muscle, fat tissue, and connective tissue).

Antibodies and Immunohistochemistry Assay

BMS 116 and BMS 125 are commercially available murine antibodies from Bender Med Systems (Vienna, Austria) with their intended use in flow cytometry, immunohistochemistry (IHC) and Western blot analysis. Working concentrations and optimal IHC conditions 

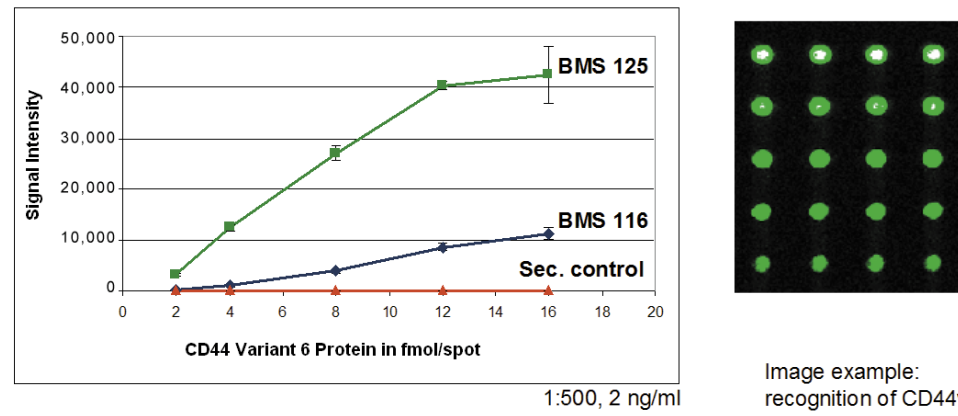

$16 \mathrm{fmol} / \mathrm{spot}$ $12 \mathrm{fmol} / \mathrm{spot}$ $8 \mathrm{fmol} / \mathrm{spot}$ $4 \mathrm{fmol} / \mathrm{spot}$ $2 \mathrm{fmol} / \mathrm{spot}$

Image example: recognition of CD44v6 by BMS125

Figure 2. Comparison of BMS antibodies 125 and 116 at 1:500 dilution binding to a printed serial dilution of cluster designation antigen identity 44 (CD44) variant 6 protein. An image example with BMS 125 is shown. Sec. control, binding of monoclonal Cy3-labeled donkey anti-mouse immunoglobulin $\mathrm{G}(\mathrm{IgG})$ in the absence of BMS antibodies.

were determined before staining of the complete set of TMAs. A final dilution of $1: 500(2 \mathrm{ng} / \mathrm{mL})$ was determined as the highest selectivity and intensity for both test antibodies. For control purposes, one TMA slide was treated with isotypematched immunoglobulin G1 (IgG1) nonspecific antibody under the same conditions.

IHC was performed according to the standard routine protocol of the laboratory at Oridis-Biomed. Briefly, slide pretreatment included $(i)$ antigen unmasking by cooking in citrate buffer at $\mathrm{pH} 9.0$ in a high-pressure pretreatment chamber and (ii) a protein blocking step by incubating the slides with $2 \%$ bovine serum albumin (BSA) for 20 min at room temperature. Detection of antibody binding was performed with the EnVision ChemMate kit (Dako, Glostrup, Denmark). Slides were then counterstained with Hemalaun and covered with the synthetic medium Entellan and a coverslip.

\section{Evaluation and Interpretation of IHC Staining}

TMAs were evaluated following imaging of the slides with a MiraxScan slide scanning device (Carl Zeiss, Jena, Germany). After scanning of the two slides, the digital images (one for BMS 116 and one for BMS 125) were displayed simultaneously on the monitor using the MiraxViewer software (Carl Zeiss) that allows coupled movement of the scans and a direct comparison of the identical areas of the two TMAs.

Like in conventional microscopy, a semiquantitative evaluation reflecting positivity and cell type could be done on the monitor. Reaction positivity was given on a four-grade scale $(0-3$, where 0 stands for negativity and $3+$ for maximum positivity), and the analysis relied on the consensus of two independent histo- pathologists (Gabor Mehes and Nikolaus Wick).

\section{Protein Biochips}

Protein biochips were manufactured by Protagen AG (Dortmund, Germany) on nitrocellulose-coated slides. They were printed with a randomly selected set of 384 different recombinant human proteins representing different gene ontology classes as published previously (UNIchip AV-400; Protagen AG) (12) or 1952 other proteins from an internal biomarker discovery project (Protagen AG, unpublished). The proteins originate from an Escherichia coli protein expression library and have been purified using a His-tag as described (13). Each recombinant human protein was printed in quadruplicates on the biochip. The UNIchip AV-400 was also printed with a serial dilution of native human CD44 variant 6 (Bender Med Systems) in the following concentrations: $10,8,6,4,2$, $1,0.5,0.2,0.1,0.05,0.025,0.01,0.001$, $0.0005,0.0001 \mathrm{pmol} / \mu \mathrm{L}$. This corresponds to $20,16,12,8,4,2,1,0.4,0.2$, $0.1,0.05,0.02,0.01,0.002 \mathrm{fmol}$ of CD44

\section{Incubation Conditions on Protein Biochips}

Each antibody was tested on two UNIchip biochips. The protein biochips were blocked in $2 \%(\mathrm{w} / \mathrm{v})$ BSA [BSA/ TBST; Tris-buffered saline with $0.1 \%$ (v/v) Tween 20] at room temperature, and the antibody sample was added in the appropriate concentration in $2 \%(\mathrm{w} / \mathrm{v})$ BSA/TBST. The protein biochips were incubated in a humidified atmosphere for $1 \mathrm{~h}$ at room temperature. The protein biochips were washed three times in TBST and subsequently incubated with the secondary antibody (monoclonal variant 6 per spot, respectively.
Cy3-labeled donkey anti-mouse IgG) in $2 \%(\mathrm{w} / \mathrm{v}) \mathrm{BSA} / \mathrm{TBST}$ for $1 \mathrm{~h}$ at room temperature, followed by three TBST washes. All antibody incubation steps were carried out in a volume of $200 \mu \mathrm{L}$ in an automated hybridization station (HS 4800 Pro; Tecan, Männedorf, Switzerland). Negative control incubations were carried out with the secondary antibody (monoclonal Cy3-labeled donkey anti-mouse IgG) only. Processed protein chips were scanned with an excitation of $550 \mathrm{~nm}$ and an emission of $570 \mathrm{~nm}$ using a confocal microarray reader (ScanArray 4000; Perkin Elmer Life Sciences, Rodgau-Juegesheim, Germany) using identical settings for all biochips. Image analysis was performed using ScanArray Express (Perkin Elmer Life Sciences).

\section{Image and Data Analysis}

Following image analysis, the mean pixel intensity (median local background subtracted) was determined for each protein spot. From each biochip, the median intensity of the four replica spots of each protein was determined. Based on all experiments for one antibody, the average of the median intensities of each protein or protein concentration is reported. To compare the UNIchip biochips, the signal intensities obtained for the 400 or 1952 human proteins were normalized using the $\operatorname{IgG}$ control spots for the secondary detection antibody as internal calibrator. As a novel method of binding profile calculation and standardization, the average signal intensity of the IgG control spots for each antibody incubation was set to $100 \%$. The average normalized signal intensity of each of the human proteins was compared to this reference value leading to relative units in percent. The cut-off level for binding activities of antibodies to the human recombinant proteins was determined from the signals in the secondary antibody incubation control by calculating the mean plus three standard deviations and corresponded to 5\% (rounded up).

\section{RESULTS AND DISCUSSION}

There is widespread interest in the determination of target specificity and potential off-target binding events of emerging biological drugs (e.g., antibodies and functionally equivalent protein scaffold binders, such as anticalins, nanobodies, and adnectins) in the clinical development pipeline of biotechnology and pharmaceutical companies. We used a novel approach applying content-rich normal TMA (FDA panel) in combination with protein biochips to characterize and 
Table 1. IHC Positivity for BMS 116 and BMS 125 in Different Cell Types of Normal Human Tissues Evaluated

\begin{tabular}{|c|c|c|c|c|}
\hline \multirow{2}{*}{ Tissue/Organ } & \multicolumn{2}{|c|}{ BMS 125} & \multicolumn{2}{|c|}{ BMS 116} \\
\hline & Cell Type & Localization & Cell Type & Localization \\
\hline Colon & 0 & 0 & Epithel & $\mathrm{N}, \mathrm{C}$ \\
\hline \multirow[b]{2}{*}{ Esophagus } & \multirow[b]{2}{*}{ Epithel } & \multirow[b]{2}{*}{ M } & Epithel & $\mathrm{M}, \mathrm{C}$ \\
\hline & & & $\begin{array}{l}\text { Leukocytes, } \\
\text { fibrocytes }\end{array}$ & $\mathrm{C}$ \\
\hline Heart & 0 & 0 & Cardiomyocytes & $\mathrm{C}$ \\
\hline Duodenum & 0 & 0 & Epithelium & $\mathrm{N}$ \\
\hline Hypophysis & 0 & 0 & $\begin{array}{l}\text { Frontal lobe } \\
\text { epithel }\end{array}$ & $\mathrm{C}$ \\
\hline Peripheral nerve & 0 & 0 & 0 & 0 \\
\hline Prostate & Myoepithel & M & $\begin{array}{l}\text { Epithel plus } \\
\text { myoepithel }\end{array}$ & $\mathrm{M}, \mathrm{C}$ \\
\hline Pancreas & 0 & 0 & $\begin{array}{l}\text { Acinar } \\
\text { epithel }\end{array}$ & $\mathrm{C}$ \\
\hline Testis & 0 & 0 & $\begin{array}{l}\text { Canalicular } \\
\text { epithel }\end{array}$ & $\mathrm{N}, \mathrm{C}$ \\
\hline Thyroid gland & 0 & 0 & $\begin{array}{l}\text { Follicular } \\
\text { epithel }\end{array}$ & $\mathrm{N}, \mathrm{C}$ \\
\hline Bone marrow & 0 & 0 & Myeloid cells & $\mathrm{N}$ \\
\hline Skeletal muscle & 0 & 0 & Fibrocytes & $\mathrm{N}$ \\
\hline Stomach & 0 & 0 & Epithel & $\mathrm{N}, \mathrm{C}$ \\
\hline Spleen & 0 & 0 & Lymphoid cells & $\mathrm{N}$ \\
\hline Tonsil & 0 & 0 & Lymphoid cells & $\mathrm{N}$ \\
\hline \multirow[b]{2}{*}{ Skin } & Epithel & M & Epithel & $\mathrm{M}, \mathrm{C}$ \\
\hline & $\begin{array}{l}\text { Sebaceous } \\
\text { myoepithel }\end{array}$ & $M, C$ & $\begin{array}{l}\text { Sebaceous } \\
\text { gland }\end{array}$ & $\mathrm{N}, \mathrm{C}$ \\
\hline Ovary & 0 & 0 & Stromal cells & $\mathrm{N}, \mathrm{C}$ \\
\hline Lung & $\begin{array}{l}\text { Alveolar } \\
\text { macrophages }\end{array}$ & $\mathrm{M}, \mathrm{C}$ & $\begin{array}{l}\text { Alveolar } \\
\text { macropahges }\end{array}$ & $\mathrm{M}, \mathrm{C}$ \\
\hline \multirow{3}{*}{ Liver } & \multirow{3}{*}{0} & \multirow{3}{*}{0} & Kupffer-cells & C \\
\hline & & & Hepatocytes & $\mathrm{N}, \mathrm{C}$ \\
\hline & & & $\begin{array}{l}\text { Endothelial } \\
\text { cells }\end{array}$ & $\mathrm{M}, \mathrm{C}$ \\
\hline Kidney & 0 & 0 & $\begin{array}{l}\text { Tubular } \\
\text { epithelium }\end{array}$ & $\mathrm{C}$ \\
\hline Brain & 0 & 0 & Glial cells & $\mathrm{N}, \mathrm{C}$ \\
\hline Cerebellum & 0 & 0 & Glial cells & $\mathrm{N}$ \\
\hline Breast & Myoepithel & $\mathrm{M}, \mathrm{C}$ & $\begin{array}{l}\text { Ductal and } \\
\text { glandular }\end{array}$ & $\mathrm{N}, \mathrm{C}$ \\
\hline Endometrium & 0 & 0 & $\begin{array}{l}\text { Glandular and } \\
\text { stromal }\end{array}$ & $\mathrm{N}$ \\
\hline Suprarenal gland & 0 & 0 & Cortical cells & $\mathrm{N}, \mathrm{C}$ \\
\hline
\end{tabular}

$\mathrm{IHC}$, immunohistochemistry; 0 , no staining observed by IHC analysis; $\mathrm{N}$, cell nucleus; $\mathrm{C}$, cytoplasm; $\mathrm{M}$, membrane.

Table 2. Overview of OTAs of the Anti-CD44 Variant 6 Antibodies BMS 116 and 125 Analyzed at Two Different Concentrations (1:500 and 1:150)

\begin{tabular}{|lllcl|}
\hline Antibody & $\begin{array}{l}\text { Total No. } \\
\text { OTAs, 1:500 }\end{array}$ & $\begin{array}{l}\text { Maximum } \\
\text { Relative } \\
\text { Units (\%) }\end{array}$ & $\begin{array}{l}\text { Total No. } \\
\text { OTAs, 1:150 }\end{array}$ & $\begin{array}{l}\text { Maximum } \\
\text { Relative } \\
\text { Units (\%) }\end{array}$ \\
\hline BMS 116 & $126^{\mathrm{a}}$ & 43 & 206 & 116 \\
BMS 125 & 1 & 5 & $2^{\mathrm{a}}$ & 11 \\
$\begin{array}{l}\text { Number of off-target activities (OTAs) on UNIchip AV 400 (384 proteins). CD44, cluster } \\
\text { designation antigen identity 44. }\end{array}$ \\
aRecommended concentrations in immunohistochemistry (IHC).
\end{tabular}

\section{Collagen Research Reagents}

\section{for bone metabolism and inflammation research}

\section{Collagen}

- Bovine type II, highly purified

- Chicken type II, highly purified

- Rat pepsin digested collagen type II

- Rat lathrytic collagen type II

\section{Collagen Antibodies}

\section{Collagen Type II ELISAs}

\section{Collagen Antibody ELISAs \\ $\lg G$ and isotypes $\lg G 2 a, \lg G 2 b$}

\section{ArthritoMab $^{\mathrm{TM}}$ \\ Anti-collagen antibody cocktail \\ for induction of arthritis}

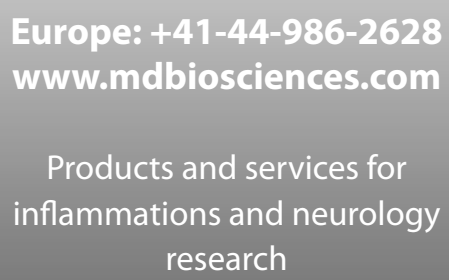


Table 3. Fingerprint of BMS 116/BMS 125 Off-Target Activities in Percent of IgG Process Control Recognition

\begin{tabular}{|c|c|c|c|c|}
\hline Protein & $\begin{array}{l}\text { BMS } 116 \\
1: 500\end{array}$ & $\begin{array}{c}\text { BMS } 116 \\
1: 150\end{array}$ & $\begin{array}{l}\text { BMS } 125 \\
1: 500\end{array}$ & $\begin{array}{c}\text { BMS } 125 \\
1: 150\end{array}$ \\
\hline Ubiquinol-cytochrome c reductase core protein II & 13 & 55 & & \\
\hline Hypothetical protein $64 \mathrm{kDa}$ & 14 & 55 & & \\
\hline Sulfotransferase 1A1 (Aryl sulfotransferase 1) & 11 & 55 & & \\
\hline S300-II; TFIIB & 22 & 56 & & \\
\hline $\begin{array}{l}\text { Lymphocyte activation-associated protein; kelch } \\
\text { (Drosophila)-like } 5\end{array}$ & 21 & 58 & & \\
\hline Unnamed protein product $36 \mathrm{kDa}$ & 13 & 60 & & \\
\hline HRIHFB2122 protein & 16 & 62 & & \\
\hline R30923_1 & 19 & 63 & & \\
\hline KIAA1885 protein & 26 & 65 & & \\
\hline HRIHFB2063 & 10 & 66 & & \\
\hline Predicted: similar to tubulin $\beta-3$ & 21 & 73 & & \\
\hline Phosphoglycerate kinase 1 & 14 & 74 & & \\
\hline $\begin{array}{l}\text { Cytosolic malate dehydrogenase; soluble malate } \\
\text { dehydrogenase }\end{array}$ & 23 & 87 & & \\
\hline Porin 31HM [human] & 24 & 88 & & \\
\hline CKB & 28 & 94 & & \\
\hline Polymyositis/scleroderma autoantigen 2 & 22 & 98 & & \\
\hline RAB6IP1 protein & 32 & 105 & & \\
\hline TPA: kinesin light chain 1B; KLC1B & 34 & 109 & & \\
\hline THOP1 protein & 41 & 111 & & \\
\hline Adaptor-related protein complex 1 & 32 & 116 & & \\
\hline $21 \%-40 \%$ & & & $1 \%-60 \%$ & \\
\hline $81 \%-100 \%$ & & & $100 \%$ & \\
\hline
\end{tabular}

Presented are the corrected off-target activities in percent of IgG process control recognition. Data are the average of eight data points; four data points/biochip and two biochips/anti-cluster designation antigen identity 44 (CD44) variant 6 BMS antibody. Control monoclonal Cy3-labeled donkey $\alpha$-mouse immunoglobulin G (IgG) antibody does not recognize any of these proteins.

validate the binding profile of commercially available anti-CD44 variant 6 antibodies (BMS 116 and BMS 125). The binding profile of both antibodies has been previously analyzed by standard Western blot analysis with pooled lung and colon carcinoma cell lines, indicating high specificity of BMS 125 antibody and low specificity of BMS 116 (data not shown). For the IHC analysis with the standardized human normal TMA panel, optimal concentration of both antibody lots were determined at a final dilution of 1:500 (following the guidelines of the FDA with the exception of using FFPE material). Gross view of the two staining reactions for BMS 125 and BMS 116 antibodies in esophagus showed significant intensity and distribution tissue components. All epithelial cell types mentioned were positive with less intensity (staining between $1+$ to $2+$ ), and additional cell types (leucocytes, tissue macrophages, stromal cells, and hepatocytes) showed reactivity with variable intensity and localization. Interestingly, in addition to membrane and cytoplasmic staining, cell nuclear positivity was observed in a number of tissues (Figures $1, \mathrm{~B}$ and D). Cell types and exact localization of IHC staining for BMS 125 and BMS 116 antibodies are given in Table 1. From this data set, we can conclude that BMS 125 exhibits a more favorable specificity pattern than BMS 116.

More recently, a humanized version of anti-CD44 variant 6 BMS 125 antibody with mertansine, a cytotoxic agent (named bivatuzumab mertansine), has been the subject of a clinical phase I trial in head and neck squamous cell carcinoma and esophagus carcinoma (14). The clinical trial was terminated due to occurrences of dermatotoxicity. This clinical occurrence is consistent with our finding of expression of CD44 variant 6 antigen on skin keratinocytes, as we have shown in our tissue prevalence analysis. Although the data are not directly comparable (mouse versus humanized BMS 125 antibody; unconjugated versus mertansine-conjugated antibody), the value and impact of such studies is apparent.

Recently, Feyen et al. (12) reported for the first time the off-target activities of three successfully marketed biotherapeutic drugs, adalimumab (Humira; Abbott, Abbott Park, IL, USA), etanercept (Enbrel; Amgen, Thousand Oaks, CA, USA and Wyeth, Madison, NJ, USA), and infliximab (Remicade; Centocor, Horsham, PA, USA), using novel protein biochips. A significant number of ribosomal proteins are recognized by etanercept and adalimumab, establishing a potential link to clinical and pathological outcomes (e.g., autoimmunity). Therefore, after completion of the histopathology review and interpretation of staining patterns and intensity by two independent pathologists, we blinded the antibodies for validation experiments using the UNIchip AV 400 for analysis of antibody specificity.

For our protein biochip experiments, serial dilutions of the CD44 variant 6 antigen were printed on the chip surface. As shown by Angenendt and coworkers, proteins can be quantitatively immobilized on nitrocellulose-coated slides, which enables quantitative assays on this surface (15). Binding curves of both BMS antibodies are shown in Figure 2, including the fluorescence image and detection by BMS 125 antibody in a dosedependent manner (16 fmol/spot-2 fmol/ spot). Antibody BMS 116 recognized its target antigen up to a maximum signal 
intensity of approximately 11,000 units, whereas antibody BMS 125 recognized its target antigen up to a maximum signal intensity of approximately 43,000 units, both antibodies were used in the same dilution as in the TMA analysis (Figure 2). The higher sensitivity of CD44 variant 6 detection of antibody BMS 125 compared with BMS 116 was also observed at a higher concentration $(1: 150,6.7 \mathrm{ng} / \mathrm{mL}$, data not shown). Thus, the antibodies BMS 125 and 116 showed a different dynamic range and detection sensitivity for their cognate antigen CD44 variant 6 (i.e., they have a different apparent affinity on the biochips).

To compare the binding profiles of both antibodies, we decided to standardize the signal intensities obtained for the 400 human proteins in a novel way by using the average of the $64 \mathrm{IgG}$ control spots for the secondary antibody detection as internal calibrator. The described binding profile calculation is a new and rational way of specificity comparison of antibodies with different apparent affinity to their cognate antigen on protein biochips. Each antibody was analyzed in two concentrations (1:150 and 1:500) on the two protein biochips. Antibody BMS 125 showed only one or two off-target activities to any of the 400 human proteins at dilution 1:500 and $1: 150$, respectively, with relatively low signal intensities of $5 \%$ and $11 \%$ or less. This indicates a high degree of specificity at both antibody dilutions and confirms the previously established conclusion derived from the TMA experiments. In contrast, BMS 116 showed many off-target activities of up to $43 \%$ in the $1: 500$ dilutions and up to $116 \%$ in the $1: 150$ dilutions, reflecting the correlation to the TMA experiments as well (Table 2). To address the question of whether 384 proteins are sufficient to allow a conclusion about specificity, we profiled the antibodies on a noncommercial protein biochip with 1952 recombinant proteins. Antibody BMS 116 (dilution 1:150) showed approximately $60 \%$ off-target activities on the noncommercial biochip compared with $54 \%$ on UNIchip AV 400 . Antibody BMS 125 (dilution 1:150) showed about $4 \%$ off-target activities on the noncommercial biochip compared with about $1 \%$ on UNIchip AV 400 indicating an unchanged ranking of the antibodies. A list of the top 18 ranking off-target activities of BMS 116 on the UNIchip AV 400 is shown in Table 3. Notably, adaptor-related protein complex $1(116 \%)$ and THOP $1(111 \%)$ are the highest off-target proteins detected by BMS 116 antibody.

The specificity profiles of the two antibodies generated by binding to the 400 respectively 1952 different proteins on the protein biochips are highly consistent with the results in the TMA analysis. The clear specificity differentiation between
BMS 125 and BMS 116 is independent of the concentrations tested in this study. Apparently, the binding sites presented on the protein biochips offer a tool for a fast ranking of antibodies according to specificity. The ranking in this study appeared to be predictive for antibody performance in IHC. Furthermore, assuming recognition of the same domain of CD44 variant 6 by BMS 125 and BMS 116, an affinity ranking of both antibodies is possible by comparing binding to the printed serial dilution of the cognate antigen. The biological meaning of the off-target activities found using the in vitro biochip assay remains to be elucidated by further studies.

Therefore, we anticipate that selecting antibodies by specificity screening on protein biochips for further analysis of off-target tissue binding using TMAs will allow faster and more efficient screening of antibody lead candidates in the early stage of preclinical development. Additionally, molecular- and cell biologybased approaches and functional assays will lead to the discovery and availability of better antibody-based drugs. One can use each of the described applications for ranking off-target activities individually or in combination due to their complementarities.

\section{ACKNOWLEDGMENTS}

The authors would like to thank Mrs. Anja Hausleitner and Mrs. Verena Trappe for their excellent technical assistance and Dr. Nikolaus Wick for independent expert review of the immunohistochemistry staining patterns of anti-CD44 variant 6 antibodies.

\section{COMPETING INTERESTS STATEMENT}

The authors declare no competing interests.

\section{REFERENCES}

1. Bradbury, A.R. and J.D. Marks. 2004. Antibodies from phage antibody libraries. J. Immunol. Methods 290:29-49.

2. Boder, E.T. and K.D. Wittrup. 1997. Yeast surface display for screening combinatorial polypeptide libraries. Nat. Biotechnol. 15:553-558.

3. Jakobovits, A., R.G. Amado, X. Yang, L. Roskos, and G. Schwab. 2007. From XenoMouse technology to panitumumab, the first fully human antibody product from transgenic mice. Nat. Biotechnol. 25:11341143 .

4. Lonberg, N. 2005. Human antibodies from transgenic animals. Nat. Biotechnol. 23:1117-1125.
5. Lueking, A., M. Horn, H. Eickhoff, K. Buessow, H. Lehrach, and G. Walter. 1999. Protein microarrays for gene expression and antibody screening. Anal. Biochem. 270:103-111.

6. Kallioniemi, O.-P., U. Wagner, J. Kononen, and G. Sauter. 2001. Tissue microarray technology for high-throughput molecular profiling of cancer. Hum. Mol. Genet. 10:657-662.

7. Simon, R. and G. Sauter. 2002. Tissue microarrays for miniaturized high-throughput molecular profiling of tumors. Exp. Hematol. 30:1365-1372.

8. Herrlich, P. 1993. CD44 splice variants: metastases meet lymphocytes. Immunol. Today 14:395-399.

9. Pals, S.T., G. Koopman, K.H. Heider, A. Griffioen, G.R. Adolf, F. Van den Berg, H. Ponta, P. Herrlich, and E. Horst. 1993. CD44 splice variants: expression during lymphocyte activation and tumor progression. Behring Inst. Mitt. 92:273-277.

10. Heider, K.H., J.W.R. Mulder, E. Ostermann, S. Susani, E. Patzelt, S.T. Pals, and G.R. Adolf. 1995. Splice variants of the cell surface glycoprotein CD44 associated with metastatic tumor cells are expressed in normal tissues of humans and cynomolgus monkeys. Eur. J. Cancer $31 \mathrm{~A}: 2385-2391$.

11. U.S. Food and Drug Administration. 1997. Points to consider in the manufacture and testing of monoclonal antibody products for human use. CBER 1-50.

12. Feyen, O., A. Lueking, A. Kowald, C. Stephan, H.E. Meyer, U. Goebel, and T. Niehues. 2008. Off-target activity of TNFalpha inhibitors characterized by protein biochips. Anal. Bioanal. Chem. 391:17131720.

13. Lueking, A., O. Huber, C. Wirths, K. Schulte, K.M. Stieler, U. Blume-Peytavi, A. Kowald, K. Hensel-Wiegel, et al. 2005 . Profiling of alopecia areata auto-antigens based on protein microarray technology. Mol. Cell. Proteomics 4:1382-1390.

14.Tijink, B.M., J. Buter, R. de Bree, G. Giaccone, M.S. Lang, A. Staab, C.R. Leemans and G.A. van Dongen. 2006. Phase I dose escalation study with antiCD44v6 bivatuzumab mertansine in patients with incurable squamous cell carcinoma of the head and neck or esophagus. Clin. Can. Res. 12:6064-6072.

15. Angenendt, P., J. Glökler, J. Sobek, H. Lehrach, and D.J. Cahill. 2003. Next generation of protein microarray support materials: evaluation for protein and antibody microarray applications. J. Chromatogr. A 1009:97-104.

Received 10 March 2008; accepted 7 May 2008.

Address correspondence to Peter Amersdorfer, Oridis-Biomed GmbH TISSOMICS Partnering, Stiftingtalstrasse 3-5, A-8010 Graz, Austria. e-mail: amersdorfer@oridis-biomed.com

To purchase reprints of this article, contact: Reprints@BioTechniques.com 